\title{
Concepções e práticas de formação continuada na educação básica
}

\author{
Santos, Edlamar Oliveira dos ${ }^{1}$ \\ Batista Neto, José
}

\section{Resumo}

O texto discute resultados de pesquisa, cujo objetivo foi analisar as concepções de formação continuada, que orientaram a política de formação docente da Secretaria de Educação, Esportes e Lazer do Recife e a organização e produção das práticas formativas com professores dos ciclos iniciais do Ensino Fundamental. Nas últimas décadas, as políticas educacionais têm atribuído ênfase à formação docente como elemento fundamental para fazer frente ao grande desafio da melhoria da qualidade do ensino. É importante destacar que nesse cenário as políticas de formação continuada assumiram um tom propositivo, ao se colocarem como caminho para a efetivação de mudanças na prática docente. Predominou nesse processo a defesa da tese de que a melhoria do ensino poderia ocorrer por meio da qualificação docente. Esse entendimento, por sua vez, contribuiu para ampliação do debate da formação continuada como política pública, orientada por leis, programas e linhas de financiamentos. O processo de investigação adotou uma perspectiva qualitativa de pesquisa. A coleta de dados realizou-se por meio de entrevistas com professores e gestores da Secretaria de Educação e observação dos encontros de formação. Procedemos, ainda, com análise de documentos oficiais relativos à formação continuada. A análise de conteúdo constituiu a nossa opção de interpretação dos dados. Como resultado, destaca-se a ideia de que as concepções e práticas de formação continuada analisadas foram estruturadas, organizadas e produzidas, considerando-se uma perspectiva de formação docente que enseja a reflexão sobre a prática pedagógica. O estudo revelou que a formação continuada é advogada como importante instrumento de melhoria da qualidade do ensino e de valorização do magistério. Reforça-se, nesse contexto, a intenção de firmar-se a relação entre formação continuada, mudança na prática docente e melhoria do ensino.

Políticas Educacionais. Formação Continuada. Prática Pedagógica.

\section{Resumen}

El texto discute los resultados de investigación, cuyo objetivo fue analizar los conceptos de formación continua, que guió la política de formación de los profesores del Departamento de Educación, Deporte y Ocio de Recife y la organización y producción

\footnotetext{
${ }^{1}$ Doutora em Educação, professora do Instituto Federal de Educação, Ciência e Tecnologia de Pernambuco, IFPE

2 Doutor em Ciências da Educação, Professor Associado do Departamento de Métodos e Técnicas de Ensino do Centro de Educação da UFPE, membro da Cátedra Paulo Freire da UFPE. E-mail: josebn@uol.com.br
} 
de las prácticas de formación con los profesores de los ciclos iniciales de la escuela primaria. En las últimas décadas, las políticas educativas han dado énfasis en la formación docente como un elemento clave para enfrentar el reto de mejorar la calidad de la enseñanza. Es importante tener en cuenta que en este escenario las políticas de formación continua han asumido un tono sugestivo una vez que se han colocado como un camino para la realización de cambios en la práctica docente. He predominado en este proceso la defensa de la tesis de que una mejora de la enseñanza podría ocurrir a través de la calificación docente. He predominado en este proceso la defensa de la tesis de que una mejoria de la enseñanza podría ocurrir a través de la calificación docente. Esta comprensión, a su vez, contribuyó a ampliar el debate sobre la formación continua como política pública, guiada por leyes, programas y líneas de financiación. La recolección de datos se realizó a través de entrevistas con los profesores y directivos del Departamento de Educación y la observación de los encuentros de formación. Seguimos con el análisis de los documentos oficiales relacionados con la formación continua. El análisis de contenido constituyó nuestra opción de interpretación de los datos. Como resultado, se destaca la idea de que los conceptos y prácticas de educación continua analizados fueron estructurados, organizados y producidos, teniendo en cuenta la perspectiva de la formación del profesorado que inspira a la reflexión sobre la práctica pedagógica. El estudio mostró que la formación continua es recomiendada como una herramienta importante para mejorar la calidad de la enseñanza y valoración de magisterio. Se subraya en este contexto la intención de establecer la relación entre la formación continua, cambio en la práctica docente y mejoria de la enseñanza.

Políticas Educativas. Formación Continua. Práctica Pedagógica

\section{Introdução}

O texto se insere no debate sobre as concepções e práticas de formação continuada de professores no âmbito da educação básica. Apresenta resultados de pesquisa, cujo objetivo foi analisar as concepções de formação continuada que orientaram a política de formação docente da Secretaria de Educação, Esporte e Lazer do Recife e a organização e produção das práticas formativas, configuradas a partir de tais concepções, considerando-se as experiências desenvolvidas com os professores dos ciclos iniciais do ensino fundamental, no período de 2001-2008.

$\mathrm{Na}$ literatura que trata da formação continuada, identificamos um conjunto de medidas políticas que resultaram na elaboração de dispositivos legais e normativos, assim como a definição de políticas de financiamento que visaram o fortalecimento de programas de formação continuada para os professores da educação básica. Outro aspecto que consideramos na literatura consultada foi a 
discussão que vem sendo tecida acerca dos modelos teóricos da formação de professores, que indicam a prática docente como espaço de produção do saber.

O processo de investigação adotou uma perspectiva qualitativa de pesquisa. A abordagem de pesquisa qualitativa, segundo as autoras, André e Lüdke (1995), configura-se como possibilidade de interpretação de dada realidade, a partir do contato direto e sistemático entre o pesquisador e a situação a ser investigada. A investigação qualitativa é descritiva e interpretativa: os dados recolhidos são transpostos, o mais fielmente possível, na comunicação dos resultados da pesquisa.

Nesse processo de busca e de deslindamento do real, o sujeito experimenta situações de aprendizagem que favorecem a ampliação e apropriação de novos conhecimentos sobre dado objeto de estudo, assim como o seu próprio desenvolvimento.

Em consonância com os objetivos da investigação, procedemos, inicialmente, com o levantamento e a seleção de documentos em que se pautaram a política de formação continuada da rede municipal de ensino do Recife. Em seguida, realizamos observações sistemáticas dos encontros de formação continuada vivenciados em uma escola municipal que atende alunos do $1^{\circ}$ e $2^{\circ}$ ciclos do ensino fundamental. Utilizamos ainda como procedimento a entrevista semiestruturada, que foi aplicada a professores (5) da escola participante da pesquisa e a gestores (3) da Secretaria de Educação, Esporte e Lazer do Recife.

A análise e a organização dos dados se deram a partir da análise de conteúdo (BARDIN, 1977), que nos permitiu codificar, categorizar e tematizar as unidades de sentido manifestadas nas mensagens. A análise se dirigiu para a organização e produção da prática pedagógica da formação continuada e as concepções de formação que a fundamentam. Para tanto, consideramos o processo de planejamento, seleção e organização dos conteúdos, estratégias metodológicas e formas de avaliação das atividades de formação realizadas com os professores do $1^{\circ}$ e $2^{\circ}$ ciclos, nos coletivos de rede e o cotidiano escolar.

A primeira parte do texto apresenta e discute aspectos relacionados às políticas de formação continuada, bem como os modelos teóricos orientadores da formação docente. Em seguida, são apresentadas as concepções e práticas 
de formação continuada adotadas pela RMER e sua relação com o cotidiano escolar.

\section{A formação continuada na educação básica: tendências teóricas orientadoras}

Tomando em consideração as reflexões sobre as tendências teóricas que orientam as práticas de formação continuada no Brasil, realizamos uma análise dos estudos organizados por Marin (2000); Candau (1997); Mizukami e Reali (1996); Carvalho e Simões (1999); Gatti (2008), entre outros. Esses autores, ao mapearem e analisarem as práticas formativas vivenciadas no Brasil dos anos 1970 aos tempos atuais, caracterizaram as grandes tendências que, historicamente, foram se constituindo como orientações teórico-metodológicas da formação e do trabalho docente.

Os estudos produzidos sobre a formação continuada destacam que, nos processos formativos desenvolvidos ao longo das décadas de 1970 e 1980, os professores foram submetidos a um modelo de formação pautado nos pressupostos da racionalidade técnica, que impunha uma visão "determinista e uniforme" sobre o seu trabalho. Esse tipo de conhecimento, referendado pela pesquisa de cunho positivista, configurou os modelos de treinamento que caracterizaram a formação continuada. Essa formação tinha por função garantir a instrumentalização técnica do professor, atribuindose um caráter de neutralidade, na medida em que ela se fazia isolada dos aspectos políticos e sociais que envolviam o ensino e o próprio processo formativo. No período aludido, a formação continuada assumiu um caráter pontual e disperso, baseado numa lógica de adaptação, desarticulado de um projeto coletivo e institucional.

A partir da década de 1990, a formação continuada inscreve suas bases numa abordagem teórica que advoga a prática pedagógica como espaço de produção do saber e, em decorrência disso, reconhece que o trabalho docente se constitui da existência de "um conhecimento tácito, espontâneo, intuitivo, experimental, um conhecimento construído no cotidiano da prática educativa" (SCHÖN, 2000; TARDIF, 2002). Em decorrência disso, houve a valorização do pensamento reflexivo sobre a prática, e o reconhecimento dos saberes elaborados no âmbito dessa prática começa a aparecer.

Em geral, podemos dizer que as proposições apresentadas pela literatura educacional vêm acompanhadas do entendimento de que a reflexão sobre a prática 
pedagógica é considerada uma estratégia importante para a formação dos professores, assim como uma possibilidade de reconstrução da identidade docente e de valorização dos seus saberes práticos. Essas questões indicam que está ocorrendo um movimento de reconceitualização da formação continuada. Assim, pudemos perceber que, em meados anos de 1990, a formação continuada passou a se apoiar em novos enfoques e/ou tendências teóricas que focalizavam a prática docente e os saberes profissionais tecidos a partir dela. Por seu turno, esses aspectos influenciaram os processos de formação de formação continuada.

Nesse novo modelo de formação, a valorização da prática e dos professores tem contribuído para se repensar concepções e práticas de formação docente, haja vista que ele oportuniza relações mais democráticas no processo de elaboração e apropriação do conhecimento. Ademais, os processos formativos construídos nessas bases potencializam reflexões mais próximas dos problemas concretos das escolas e dos professores, o que, consequentemente, tem ajudado a estabelecer novos vínculos com a realidade escolar e com a prática docente.

Contudo, chamamos a atenção para o fato de que o saber prático não é suficiente para fundamentar uma perspectiva que se proponha a compreender a multidimensionalidade do trabalho docente. O olhar demasiado sobre as questões imediatas do ensino pode incorrer no risco de contribuir para o desenvolvimento de uma prática formativa baseada num praticismo e/ou na supervalorização do professor como sujeito individualizado.

A prática reflexiva, não raramente, tem sido evocada como panaceia dos problemas educacionais, aspecto que tem contribuído para deslocar o eixo da problemática da qualidade do ensino, na medida em que a preocupação sai do âmbito relativo à sociedade em seu conjunto e recai no campo técnico-pedagógico, relativo, sobretudo, à prática do professor. Como se sabe, porém, não é só a formação do professor que precisa passar por mudanças, mas as demais condições que possibilitam a superação dos problemas que envolvem a atividade educativa.

\section{Políticas de formação continuada}

Os desafios gerados pelas mudanças da sociedade contemporânea e a existência de uma agenda de reforma na educação, com o intuito de solucionar os problemas sinalizados pelos resultados do ensino, são fatores que contribuíram para enfatizar o papel da formação docente nas políticas educacionais dos anos de 1990. Nesse 
processo, a formação continuada passou a se fazer presente entre as preocupações das políticas, assumindo um tom propositivo, ao se colocar como caminho para a efetivação de mudanças na prática docente. Em decorrência disso, foram formulados e implementados projetos e programas que inicialmente se voltaram para o professor do Ensino Fundamental, mas que hoje abrangem os diferentes níveis, etapas e modalidades da educação básica.

A defesa do pressuposto de que a melhoria do ensino pode ocorrer por meio da qualificação docente contribuiu, em definitivo, para a institucionalização da formação continuada. Sendo assim, desde a década de 1990, o Ministério de Educação (MEC), em parceria com os sistemas de ensino, vem ampliando e conformando novos programas de formação continuada e formação em serviço para os profissionais da educação básica. Nessa direção, o MEC se incumbiu da elaboração e da implementação de um conjunto de marcos legais e regulatórios, com o objetivo de promover o desenvolvimento de uma agenda de formação continuada em nível federal, estadual e municipal. Entre os normativos legais, destacamos, para efeito de análise, a LDB, Lei 9394/96, o PNE, Lei 10.172/2001 e a Portaria no 1403/2003, que instituíram a Rede Nacional de Formação Continuada. Esses documentos, ao tratarem dessa modalidade de formação, definiram concepções, diretrizes, procedimentos e recursos que determinaram uma política de formação e valorização para o magistério.

$\mathrm{Na}$ análise que fizemos da formação continuada na LDB 9394/96, três aspectos nos chamaram a atenção. O primeiro aspecto que evidenciamos tem a ver com as discussões conceituais que perpassam os termos apresentados no corpo da lei. No Art. 61, Inciso I, a formação continuada é considerada como capacitação em serviço; no Art. 67, Inciso II, ela aparece como aperfeiçoamento profissional continuado e no Art. 87 destaca-se como treinamento em serviço. A diversidade de terminologias não guarda somente uma questão semântica. Ela traduz as finalidades de uma concepção de formação continuada, que se inscreve no movimento de materialização de uma lei que priorizou a construção de mecanismos capazes de responder aos compromissos firmados na Conferência de Jontiem. Mais que confusões terminológicas, esses conceitos traduzem uma concepção de formação e de professor que serviu de sustentação para o desenvolvimento de políticas de formação docente de caráter técnico-instrumental, orientadas por uma perspectiva compensatória.

No que diz respeito à regulamentação, o estudo de Gatti (2008) revelou que, em meados da última década do século passado, a formação continuada apresentou crescimento exponencial com o advento da Lei de Diretrizes e Bases 
(LDB 9394/96). Na LDB, a formação continuada aparece como direito do professor e como instrumento de profissionalização, determinando que a mesma deve ser oferecida aos profissionais da educação dos diversos níveis de ensino. O Art. 67, Inciso II, estabelece que os sistemas de ensino deverão assegurar a formação dos docentes em exercício como um direito do professorado, integrante de sua carreira e de política de valorização do magistério.

O segundo aspecto diz respeito ao espaço ocupado pela formação continuada no âmbito da lei. Essa modalidade de formação aparece como direito do professor e como um dos instrumentos de valorização profissional que deve estar, inclusive, assegurado nos termos dos estatutos e dos planos de carreira do magistério público, conforme podemos verificar no Art. 67 da referida Lei. Nesse artigo também são definidos, simultaneamente, os princípios orientadores da valorização do magistério, o piso salarial profissional, a progressão funcional, as condições adequadas de trabalho e o aperfeiçoamento profissional continuado.

O terceiro aspecto que ressaltamos na LDB reside na caracterização da formação continuada como sendo formação em serviço. Essa questão se manifesta de forma contundente no Art. 87, $\S 4^{\circ}$, o qual advoga que "até o fim da década da educação somente serão admitidos professores habilitados em nível superior ou formados por treinamento em serviço". Esse entendimento contribuiu para a proliferação de programas especiais que, em nome da qualificação docente, legitimaram cursos que, não raramente, contribuíram para um processo de formação aligeirada do professor. Outra nuance desse processo foi a restrição da concepção de formação continuada a uma perspectiva compensatória, que se expressou por meio de programas de formação especiais ou programas de treinamento voltados, principalmente, para os aspectos curriculares e metodológicos.

A garantia da formação continuada do professor trouxe, ainda, a necessidade de se repensar a ampliação de recursos para a manutenção e o desenvolvimento da formação docente. Sendo assim, o Governo Federal se ocupou de regulamentar uma política de financiamento sistemático, por meio do Fundo de Manutenção e Desenvolvimento do Ensino Fundamental e Valorização do Magistério (Fundef), instituído pela Lei 9422/1996. O Fundef teve uma dupla finalidade, na medida em que visou à articulação de recursos voltados à universalização do ensino fundamental e à valorização do magistério, por meio do pagamento de salários e da instituição de planos de carreira e formação em 
serviço. Embora o Fundef tenha apresentado limites quanto ao seu funcionamento, podemos perceber que o mesmo se propôs a contemplar o desenvolvimento profissional do docente. É importante salientar que o Fundef foi substituído em 2007 pela Lei n 11.494, que instituiu o Fundo de Manutenção e Desenvolvimento da Educação Básica e de Valorização dos Profissionais da Educação (Fundeb). A referida política ampliou a perspectiva de universalização do ensino, na medida em que estendeu o alcance dos recursos alocados para a manutenção e desenvolvimento de toda a educação básica e manteve a perspectiva de valorização dos profissionais do magistério.

A LDB 9394/96 e o Fundef dedicaram um lugar para a formação continuada e advogam-na como direito do professor e como dever do Estado, fatores esses que são importantes para institucionalização da formação enquanto política pública. Contudo, teria sido necessário o estabelecimento de critérios quanto à oferta das ações formativas, pois a demanda observada acelerou o crescimento de um mercado rentável. A mercantilização da formação continuada nos leva a pontuar as seguintes questões: a não valorização das secretarias de educação como instituições que formulam e implementam políticas de formação docente, ficando limitadas a uma prática aplicacionista, o silenciamento da voz do professor na definição das políticas e o fortalecimento de uma concepção de formação continuada que, muitas vezes, tem se ocupado somente da certificação, distanciando-se de uma perspectiva de desenvolvimento pessoal, profissional e institucional.

A formação continuada também foi tratada no Plano Nacional de Educação (PNE), Lei 10.172/2001, que traçou objetivos e metas para formação de professores e valorização do magistério. No PNE, "a formação continuada assume particular importância, em decorrência do avanço científico e tecnológico e de exigência de um nível de conhecimentos sempre mais amplos e profundos da sociedade moderna" (2001, p. 67). Nesse sentido, o plano diz que "deverá dar especial atenção à formação permanente (em serviço) dos profissionais da educação" (PNE, 2001). De acordo com essa lógica, percebemos uma valorização da formação continuada como estratégia de 
qualificação profissional face às exigências da "sociedade do conhecimento e/ou sociedade da informação".

A formação permanente aparece, nesse contexto, como caminho necessário à configuração de um novo processo educativo em que os professores, como protagonistas, necessitam se atualizar permanentemente para desempenhar tarefas que estão sempre a se transformar, em decorrência das mutações técnico-científicas. Com essa ideia de formação permanente, percebemos que prevalece no PNE uma concepção de formação continuada que, muitas vezes, tem favorecido o desenvolvimento de práticas formativas voltadas para a atualização de conteúdos, métodos ou técnicas, com o intuito de promover a modernização da escola e do ensino. Vê-se, assim, que o PNE e a LDB guardam semelhanças quanto à assunção de uma concepção de formação continuada alinhada aos interesses da reforma educativa implementada no início da década de noventa.

Ainda em consonância com esse ideário, o PNE (2001) defende a tese de que "a formação continuada é parte essencial da estratégia de melhoria permanente da qualidade da educação, e visará à abertura de novos horizontes na atuação profissional". Reafirma-se o protagonismo docente como caminho para a efetivação da qualidade do ensino. O PNE estabelece conformidade ainda com a LDB quando explicita que essa modalidade de formação deverá ser assegurada pelas "secretarias de estaduais e municipais de educação, cuja atuação incluirá a coordenação, o financiamento e a manutenção dos programas como ação permanente e busca de parcerias com universidades e instituições de ensino superior". A partir dessa ideia, as justificativas que se põem apontam para a criação de um sistema de formação continuada constituído pelo conjunto dessas instituições. Outro aspecto de similitude entre os documentos aludidos é a valorização da modalidade de educação a distância na realização dos programas de formação continuada.

Com relação às diretrizes políticas assumidas pelo MEC no campo da formação continuada, a partir de 2003 , destaca-se a criação da Rede Nacional de Formação Continuada de Professores da Educação Básica (RNFC). A história de criação dessa rede remonta ao processo de implantação da Portaria 
MEC $n^{\circ}$ 1403, de 09 de junho de 2003, que instituiu o Sistema Nacional de Certificação e Formação Continuada de Professores. Dentre os objetivos desta Rede, destacam-se o compromisso com a melhoria do ensino e a qualificação docente. Visa, ainda, uma articulação entre as instituições formadoras e a socialização dos conhecimentos produzidos sobre a educação com os professores da educação básica. Para tanto, recomenda que essa formação seja desenvolvida por meio da Rede Nacional de Formação Continuada (RNFC), que deverá coordenar e implementar os programas: Gestar I (professores dos anos iniciais do Ensino Fundamental), Gestar II (professores dos anos finais do Ensino fundamental) e o Pró-letramento. Tais programas priorizam as áreas de Língua Portuguesa e Matemática e Alfabetização. Sugere-se ainda que a formação continuada garanta maior protagonismo dos docentes, privilegiando estudos e reflexões coletivas sobre a prática pedagógica.

A implantação da Rede Nacional de Formação Continuada inaugurou uma nova fase da formação docente, na medida em que anuncia duas questões pouco valorizadas pelas políticas anteriores: a institucionalização da formação continuada, por meio dos Centros de Pesquisa e Desenvolvimento Escolar, pertencentes às universidades públicas e comunitárias, e a construção de uma perspectiva de formação continuada que propugna o desenvolvimento de uma atitude investigativa e reflexiva sobre a prática de ensino e a valorização do próprio local de trabalho como espaço da formação. Observamos, ainda, que a referenciada Rede busca estabelecer um diálogo com o aspecto da valorização profissional, aproximando-se, assim, de pontos propostos pela LDB 9394/96 e pelo PNE 2001, e aponta para a necessidade de uma política de financiamento que se estenda a toda educação básica (Fundeb), como forma de promover a sua universalização, a melhoria da qualidade do ensino e a qualificação dos profissionais da educação.

É importante registrar que o discurso da formação continuada manifestado pela Rede Nacional de Formação Continuada, embora tenha um tom propositivo nos aspectos já pontuados, ainda apresenta resquícios de uma política focalizada, principalmente quando prioriza o desenvolvimento de pesquisas aplicadas com relação aos conteúdos dos anos iniciais do ensino fundamental, 
tecnologias de gestão e avaliação. Nesse marco, vemos emergir numa perspectiva de formação continuada que visa à melhoria da qualidade do ensino, sobretudo daqueles aspectos vinculados aos indicadores de desempenho, que denotam fragilidades nas aprendizagens dos alunos. O foco da formação é, portanto, a aprendizagem do aluno, mas não qualquer aprendizagem, mas, sim, aquela que garanta a aquisição de determinadas competências a serem avaliadas em testes padronizados.

É oportuno observar que o Plano de Desenvolvimento da Educação (PDE) implantado pelo governo Lula, em abril de 2008, reafirmou o discurso da formação continuada como decisiva na conquista da melhoria do ensino ofertado pela educação básica. O PDE sustentava o discurso de que "a melhoria da qualidade da educação básica depende da formação de seus professores, o que decorre diretamente das oportunidades oferecidas aos docentes" (PDE, 2007, p.10). Nesse contexto, reforça-se a ideia do professor como protagonista dos projetos educativos, o que fortalece o discurso da formação continuada e da profissionalização e ratifica a convocação das redes de ensino para consecução deste objetivo.

\section{Concepções e práticas formação continuada na Rede Municipal de Ensino do Recife}

A educação municipal da cidade do Recife passou ao longo dessas últimas três décadas por mudanças no seu quadro político, que, invariavelmente, têm significado descontinuidades de ações no âmbito das políticas educacionais. Braga (2008) observou que tais mudanças são relativas às divergências de caráter político que durante as últimas administrações do município vêm se alternando entre um franco conservadorismo, observado na gestão de Roberto Magalhães (1997-2000), e os modelos progressistas democráticos, com Jarbas Vasconcelos (1986-1988) e o prefeito João Paulo, em seus dois mandatos consecutivos (2001-2004 e 2005-2008).

No que tange às políticas educacionais, o estudo revelou que a RMER, desde o final dos anos de 1980, comprometeu-se com o desenvolvimento de experiências de caráter político-pedagógico (Ciclo de Alfabetização, 1986; Tecendo a Proposta da Rede, 1993 e Ciclos de Aprendizagem, 2001) que anunciaram à necessidade de se criarem as condições para o desenvolvimento de uma prática educativa de cunho propositivo, 
como possibilidade de atendimento das demandas das classes populares, no que diz respeito à democratização do ensino. Pudemos observar, ainda, que essas propostas vieram acompanhadas pelo desenvolvimento de políticas de formação continuada para os professores. Tais políticas tinham por objetivo contribuir com a reinvenção da prática educativa e a melhoria do trabalho docente, com vistas a promover melhoria na aprendizagem do aluno.

Nessa direção, as experiências citadas tomaram a formação continuada como estratégia para efetivar mudanças na prática do professor, o que possibilitou que ela fosse conquistando seu lugar, construindo sua identidade e se constituindo, enquanto política plenamente inserida no cotidiano dessa rede de ensino.

A gestão educacional instalada no período de (2001-2008) cunhou uma política educacional pautada no desenvolvimento de ações no âmbito da gestão, do currículo, da avaliação e nas questões relativas à profissionalização docente (formação, concurso, revisão de plano de cargos e salários). No que tange à formação continuada, a Secretaria de Educação, Esportes e Lazer do Recife se comprometeu, ao longo da gestão em análise, com o desenvolvimento de uma política sistemática, direcionada aos professores dos diferentes níveis e modalidades de ensino da RMER. Ademais, na medida em que foram se intensificando os desafios quanto à melhoria do ensino oferecido pela rede de ensino, a gestão da Secretaria de Educação, Esportes e Lazer do Recife passou a dedicar atenção especial à ampliação das estratégias de formação continuada, bem como a investir em possibilidades de criação de alternativas que pudessem concorrer para o desenvolvimento da formação continuada no âmbito da escola.

Ainda que se considere que essa gestão manteve uma perspectiva de continuidade, a pesquisa evidenciou que houve algumas mudanças de foco no encaminhamento das políticas voltadas para o ensino, que, de alguma forma, influenciaram no trato das questões relacionadas à formação continuada. Num primeiro momento, o projeto de educação municipal voltou-se para ampliação das possibilidades de acesso à escola para, num segundo momento, centrar seu olhar na permanência do aluno, com a oferta de um ensino com qualidade. Não podemos deixar de destacar também que, na primeira gestão de João Paulo (2001 a 2004), a Secretaria de Educação, Esportes e Lazer do Recife precisou lidar com políticas educacionais de cunho neoliberal implementadas pelo governo de FHC. Esse fator, provavelmente, exigiu políticas mais alinhadas ao debate político sobre as finalidades da escola, relacionadas à democratização da escola e do ensino. Afinal, essa era a tônica 
assumida pelas políticas educacionais que se colocavam na contramão do projeto de educação neoliberal.

A política de formação continuada da Secretaria de Educação, Esportes e Lazer do Recife combinou diferentes práticas formativas que traduziram objetivos $\mathrm{e}$ concepções de formação, materializando formas diferenciadas de organização e produção das práticas formativas. Quanto às ações e aos programas de formação, a Secretaria de Educação, Esportes e Lazer do Recife investiu, entre 2001 e 2008, na realização de atividades elaboradas e executadas pela própria Secretaria, a exemplo dos estudos intensivos, oficinas, seminários de socialização, etc. e em programas implementados pela Rede Nacional de Formação Continuada - MEC (Pró-letramento) e programas do Centro de Estudos, Educação e Linguagem - CEEL (Professor Alfabetizador). Além disso, ofereceu ações voltadas para formação inicial em serviço, por meio do Programa Especial de Graduação em Pedagogia (Progrape), e normatizou formas de participação do professor em encontros científico-acadêmicos e cursos de pós-graduação. Esse quadro demonstra que a Secretaria de Educação, Esportes e Lazer do Recife desenvolveu nesse período um conjunto de ações e programas que traduzem diferentes formas de se pensar e fazer a formação continuada na RMER.

\subsection{O diálogo com as práticas de formação continuada desenvolvidas pela Secretaria de Educação, Esportes e Lazer do Recife}

O estudo evidenciou que há, por parte da Secretaria de Educação do Recife, uma preocupação em definir diretrizes que ajudem a conformar uma política de formação continuada para os seus professores, associando-a à conquista da melhoria do ensino e da aprendizagem do aluno. Nesse sentido, observamos que a política de formação continuada da Secretaria de Educação, Esportes e Lazer do Recife está alicerçada no discurso da melhoria da qualidade do ensino. Em razão disso estabelece relações de congruência com os aspectos relacionados à necessidade de criação de novas formas de intervenção didático-pedagógica no ensino e, em decorrência disso, assume uma concepção de formação continuada que enfatiza a reflexão sobre a prática docente, pois parte da compreensão de que tais mudanças implicariam na melhoria do processo de ensino-aprendizagem. Em que pese as especificidades de cada uma das práticas analisadas, pudemos observar que prevaleceu, como elemento comum, o desejo de provocar melhoria no ensino, mediante a qualificação docente.

Os dados analisados indicaram que as concepções e práticas de formação continuada, assumidas e materializadas pela gestão da Secretaria de Educação, 
Esportes e Lazer do Recife, no período aludido, aproximam-se de uma perspectiva teórica que defende a reflexão sobre a prática pedagógica como eixo estruturante. Vale ressaltar que ao longo da gestão essa perspectiva foi assumindo contornos diferenciados, os quais têm relação com as exigências postas para o ensino, para o trabalho do professor, bem como para as demandas do contexto socioeducacional.

A reflexão sobre a prática pedagógica, embora tenha sido a concepção de formação assumida ao longo da gestão da Secretaria de Educação, Esportes e Lazer do Recife, entre 2001 e 2008, não se desenvolveu de forma única, bem como não teria orientando a política em questão em única direção. Observamos que em alguns momentos essa perspectiva da reflexão esteve voltada para questões mais amplas da educação, sobretudo no período de implantação da proposta político-pedagógica da RMER - "Ciclos de Aprendizagem". Nesse período, a formação continuada se caracterizou pela realização de encontros acadêmico-científicos semestrais, aspecto que, segundo os professores participantes da pesquisa, dificultou uma reflexão sistemática das questões cotidianas que envolvem a escola e o ensino. Por outro lado, esses mesmos professores reconhecem a importância desse tipo de formação e alguns demandam a sua continuidade.

No momento posterior, a reflexão sobre a prática pedagógica apareceu mais vinculada aos aspectos do ensino. Essa tendência foi evocada pela Secretaria de Educação, Esportes e Lazer do Recife como um caminho necessário à consolidação das mudanças pretendidas com a política curricular de ciclos. A partir dessa perspectiva, ela investiu na construção de processos formativos que pudessem promover uma reflexão mais sistemática da prática pedagógica no cotidiano da escola. Essas questões demonstram que a Secretaria de Educação, Esportes e Lazer do Recife ressignificou as práticas de formação continuada, na tentativa de garantir uma intervenção direta no ensino e no trabalho do professor e assim enfrentar os problemas da qualidade do ensino. Para tanto, desenvolveu ações e implantou programas que têm um olhar mais direcionado para sala de aula, bem como criou algumas condições para efetivação de processos formativos no âmbito do cotidiano escolar.

Com relação à formação continuada na escola, observamos que esse processo foi tecido a partir das orientações contempladas no Programa Pró-letramento, cuja ênfase recai no ensino de Alfabetização, Linguagem e Matemática. Nesse processo, tornou-se importante o resgate do coordenador pedagógico como profissional responsável pela formação de seus pares na escola. Além da formação no cotidiano escolar, a Secretaria de Educação, Esportes e Lazer do Recife elaborou e implementou 
ações que se efetivaram por meio de encontros coletivos de rede, nos quais os professores tinham oportunidade de participar de atividades diferenciadas, tais como: cursos de atualização curricular e didático-pedagógica, seminários de socialização de experiências e oficinas pedagógicas. Nessas atividades, o foco também estava nas questões do ensino.

Com relação à organização da prática pedagógica da formação continuada, observamos que a prática reflexiva tecida nos processos formativos estava permeada por um movimento contraditório. De um lado, revelava a preocupação da Secretaria de Educação, Esportes e Lazer do Recife com as experiências das escolas e do professor e, por outro, indicava uma visão reducionista de prática, sobretudo quando não se conseguia estabelecer relação com os demais elementos que integram o trabalho docente. A prática pedagógica insere-se na prática social mais ampla, envolve um conjunto de condicionantes históricos, políticos, sociais e culturais que, no nosso entendimento, não podem ser desvelados e interpretados somente pelo fazer imediato do professor. Dessa maneira, a formação teórica é fundamental para que o docente compreenda a educação e os elementos integrantes do seu trabalho. Caso contrário, a formação pode vir a assumir um caráter puramente técnico-instrumental.

No que diz respeito à organização das práticas formativas desenvolvidas nos coletivos de rede e no cotidiano escolar, a pesquisa evidenciou essa tensão. Percebemos ainda que as práticas formativas que não conseguiram desenvolver estratégias metodológicas que favorecessem a reflexão sobre a prática pedagógica estruturaram-se valorizando a disseminação de conteúdos curriculares e/ou inovações didático-pedagógica. De forma geral, a organização da prática pedagógica revelou o desenvolvimento de práticas formativas nos espaços coletivos de rede e no cotidiano escolar, centradas no conteúdo curricular e no professor formador. Caracterizaram-se também pelas dificuldades dos professores formadores em articular conhecimento disciplinar e conhecimento pedagógico; pelas dificuldades para desenvolver uma metodologia que favorecesse a problematização da prática pedagógica e sua relação com a prática social mais ampla e por reflexões sobre a prática pedagógica limitadas ao fazer imediato, desprovidas de fundamentação teórica.

Nenhuma dessas características impediu que os professores participantes da pesquisa deixassem de reconhecer a importância da formação continuada no seu processo de desenvolvimento profissional, assim como não os fez deixar de destacar o esforço da Secretaria de Educação, Esportes e Lazer do Recife em oferecer uma formação que fosse capaz de articular conteúdos curriculares (o que ensinar) e 
elementos didático-pedagógicos (como ensinar). Porém, nesse processo, não escaparam as preocupações dos professores quanto aos limites da formação continuada, sobretudo quando relacionam sua atividade profissional às condições de trabalho que dispõem para realizá-las, bem como as condições de formação.

A pesquisa revelou que a perspectiva de formação continuada que valoriza a reflexão sobre a prática pedagógica implica um conjunto de condições que vão além das questões que envolvem mudanças nos processos formativos, ou seja, ela se vincula não somente a uma questão epistemológica e/ou pedagógica, mas às condições oferecidas para o professor se formar e desenvolver o seu trabalho. Daí porque salientamos a inviabilidade de se estabelecer uma relação direta entre qualidade do ensino e formação continuada, sob pena de cairmos numa visão unidirecional de culpabilização do professor pelos problemas relativos à crise do ensino.

No que diz respeito às condições de produção das práticas formativas, a pesquisa revelou que tais práticas fazem parte de um processo vivo e dinâmico, no qual se inscrevem os problemas gerais da educação. Assim, embora tenhamos percebido que a gestão da Secretaria de Educação, Esportes e Lazer do Recife tem demonstrado certo empenho no trato das questões relativas à formação continuada do professor, as condições oferecidas para a efetivação da formação ainda não são suficientes para atender às necessidades dos professores. Nesse sentido, levantamos algumas preocupações que foram sendo apontadas, na medida em que analisávamos o processo de organização e produção das práticas formativas vivenciadas nos espaços coletivos de rede e no cotidiano escolar.

Uma das primeiras preocupações diz respeito à necessidade de se garantir condições favoráveis para a formação continuada. Essa preocupação provém dos limites que observamos quanto à garantia do espaço e tempo para que essa formação se efetivasse. No geral, a Secretaria de Educação, Esportes e Lazer do Recife não mexeu com as estruturas relativas às condições de trabalho do professor. Pelo contrário, utilizaram-se de mecanismos paliativos, que, se por um lado adequaram os processos formativos à complexa realidade da Rede Municipal de Ensino de Recife e das condições de trabalho e funcionais de seus professores, por outro, trouxeram implicações que indicavam uma situação não muito vantajosa para o professor adquirir uma formação consistente e de qualidade.

A segunda preocupação se refere aos limites do Programa Movimento de Aprendizagem Interativa (Mais), criado com o objetivo de oportunizar estagiários para substituírem o professor durante as atividades de formação continuada, no horário de 
regência da sala de aula. Foi possível constatar que tal medida, embora tenha sua importância, não conseguiu garantir a equidade no acesso à formação, aspecto que interferiu negativamente para que se efetivassem dois princípios da política de formação continuada da Secretaria de Educação, Esportes e Lazer do Recife: a formação como direito do professor e a valorização da escola como espaço de formação. Ambas as questões denotam que uma política de formação continuada vai além da oferta de cursos, pois implica em determinadas condições que passam por transformações necessárias às condições de trabalho, salário e carreira.

A terceira preocupação diz respeito à formação no cotidiano escolar. O estudo revelou que esse tipo de formação vem acontecendo por meio de programas elaborados e organizados por instâncias externas à escola, aspecto que indica a necessidade da Secretaria de Educação, Esportes e Lazer do Recife estimular as escolas a formularem seus próprios programas de formação continuada, assim como oferecer condições para as escolas e os professores se envolverem em processos colaborativos de formação e de trabalho. De toda maneira, apesar das dificuldades decorrentes da implantação e funcionamento da formação no cotidiano escolar, a pesquisa revelou que a experiência vivenciada com o Programa Pró-letramento favoreceu a garantia de espaço e tempo para formação continuada no âmbito da escola, bem como resgatou o papel do coordenador pedagógico como profissional responsável pela formação dos seus pares, pela mediação das questões pedagógicas no âmbito da escola. Os professores participantes da pesquisa foram enfáticos em ressaltar esses aspectos, além do Programa Pró-letramento como um dos pontos positivos na política de formação continuada da Secretaria de Educação, Esportes e Lazer do Recife.

A quarta preocupação que levantamos acerca da produção das práticas formativas se refere à presença do professor tutor no âmbito da formação continuada. A experiência de tutoria na RMER expressou, por um lado, fatores positivos e, por outro, aspectos passíveis de discussão, haja vista o seu caráter contraditório. Sobre este último aspecto, destacamos a perspectiva de reprodução e/ou de "passa-repassa", que as ações e programas de formação continuada têm assumido por intermédio das práticas de tutorias. Compreendemos a importância de um quadro próprio de formadores da Secretaria de Educação, Esportes e Lazer do Recife, bem como do coordenador pedagógico. Entretanto, esse quadro de formadores também necessita dispor de algumas condições de formação e de condições de trabalho.

Por fim, destacamos que é inegável que a gestão da Secretaria de Educação, Esportes e Lazer do Recife experimentou avanços na concepção de formação 
continuada, ao aproximar suas políticas de algumas questões pontuadas no debate político-epistemológico do campo da formação docente, pois ajudaram a Secretaria de Educação, Esportes e Lazer do Recife a vislumbrar novos processos formativos.

\section{Considerações}

No âmbito dos documentos de caráter mandatário (LDB e PNE), percebemos que os mesmos definem princípios e diretrizes comuns no tocante à formação continuada do professor, sobretudo no que se refere ao fortalecimento de um discurso que advoga a melhoria da qualidade do ensino como decorrência de um intenso processo de qualificação docente. Além disso, os documentos evidenciam uma vinculação da formação continuada com o processo de atualização do professor às necessidades da sociedade contemporânea. Esse quadro contribuiu para a proliferação de diferentes ações e programas de formação continuada, que, não raramente, cumpriram a tarefa de simplesmente certificar os professores e/ou preencher lacunas de uma formação inicial considerada insuficiente. Em decorrência disso, houve uma aceleração no crescimento do mercado da formação continuada e o fortalecimento de uma perspectiva de formação em serviço.

Na pesquisa que realizamos, percebemos que existe por parte da Secretaria de Educação, Esporte e Lazer do Recife, no período 2001-2008, um esforço em construir uma política de formação continuada de caráter sistêmico e sistemático. Nesse sentido, a Secretaria de Educação, Esportes e Lazer do Recife investiu na criação de uma infraestrutura (equipamentos, material pedagógico, quadro de professores formadores e estagiários, etc.) para a realização das atividades de formação em rede e nas escolas. Assumiu igual importância os investimentos quanto às discussões acerca das concepções e práticas de formação continuada presentes na rede e no debate nacional que trata da formação docente.

A definição de princípios, diretrizes e ações no âmbito da política estudada contribuiu para o fortalecimento de uma perspectiva teórica de formação continuada que se aproxima dos ideais da epistemologia da prática. Porém, se torna importante avançar nas práticas de formação, sobretudo em ações que considerem os processos pelos quais os professores se apropriam e constroem seus conhecimentos e suas experiências pessoais e profissionais.

A articulação entre formação e profissionalização se constitui como uma necessidade muito recorrente nas falas dos sujeitos desta pesquisa. A garantia da jornada de trabalho em uma única escola e a melhoria nas condições de trabalho e de 
formação se tornam importantes para a efetivação de um projeto pedagógico compromissado com a conquista de uma educação pública de qualidade socialmente referenciada. É evidente que a formação do professor não é a "formula mágica" para resolver todos os males da educação, todavia, não se pode deixar de considerar que esta desempenha um papel importante na construção de novas experiências educacionais.

Sem desconsiderar a importância dos investimentos feitos no campo da formação continuada, parece ser necessário ampliar as reflexões sobre os princípios, finalidades e pressupostos teóricos subjacentes às políticas de formação continuada que estão sendo implementadas. Convém lembrar que permanece a defesa da profissionalização dos professores, mediante uma sólida formação e a alteração de suas condições de trabalho.

\section{Referências}

ANDRÉ, Marli Eliza D. A de. Etnografia da prática escolar. 8. ed. Campinas, SP: Papirus, 1995.

BARDIN, Laurence. Análise de conteúdo. Lisboa, Portugal: Edições 70 Ltda., 1977.

BRAGA, Maria do Carmo; BRAGA, Silvia Helena Félix. Gestão democrática no Recife: o uso do orçamento participativo como parâmetro de análise. Humanae, v. 1, n. 2, p. 37-54, dez. 2008.

BRASIL. Ministério de Educação. Pró-letramento: programa de formação continuada de professores das séries iniciais do ensino fundamental. Alfabetização, Linguagem e Matemática. Brasília: MEC, 2006.

. Ministério de Educação. Lei no 9394/06. Lei de Diretrizes e Bases da Educação Nacional. Brasília: MEC, 1996.

Ministério de Educação. Lei no 9422/1996 - FUNDEF. Regulamenta o

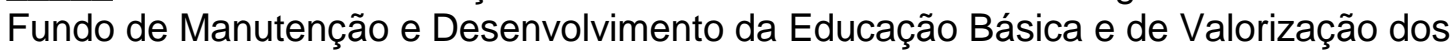
Profissionais da Educação - FUNDEB. Brasília, MEC, 1996.

. Ministério de Educação. Lei no 11.494/2007 - FUNDEB. Regulamenta o

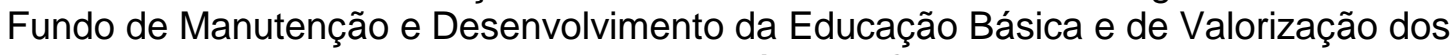
Profissionais da Educação - FUNDEB. Brasília, MEC, 2007.

Ministério de Educação. Lei no 10.172/2001. Plano Nacional da Educação. Brasília: MEC, 2001.

. Ministério de Educação. Portaria no 1403. Institui o Sistema Nacional de Certificação e Formação continuada. Brasília: MEC, 2003. 
. Ministério de Educação. PDE: Caderno de Orientações. Brasília: MEC, 2007.

CANDAU, Vera Maria (Org.). Magistério: construção cotidiana. 4ª ed. Petrópolis, RJ: Vozes, 1997.

CARVALHO, Janete Magalhães; SIMÕES, Regina Helena Silva. O que dizem os artigos publicados em periódicos especializados, na década de 90 sobre o processo de formação continuada do professor. In: 22ª Reunião da ANPED. Caxambu-MG, 1999.

GATTI, Bernadete A. Análise das Políticas Públicas para Formação Continuada no Brasil, na última década. Revista Brasileira de Educação, Rio de Janeiro, n. 37, p.57-70, jan/abr., 2008.

GOVERNO DO ESTADO DE PERNAMBUCO. Os ciclos de aprendizagem e a organização escolar. Recife: Secretaria de Educação do Recife, Fev, 2002.

Política de formação continuada e formação de leitores: versão Preliminar. Secretaria de Educação Municipal - Diretoria de Ensino. (mimeo). Recife, 2005.

MARIN, Alda Junqueira. Educação continuada. Campinas, SP: Papirus, 2000.

MIZUKAMI, Maria das Graças e REALI, Aline Maria de Medeiros Rodrigues (Orgs. Formação de professores: tendências atuais. São Carlos: EduFSCar, 1996.

NÓVOA, Antônio. Os professores na virada do milênio: do excesso dos discursos à pobreza das práticas. Educação e Pesquisa, São Paulo, v 25, n. 1, p. 11-20, jan/jun. 1999.

SCHÖN, Donald. Formar professores reflexivos. In: NÓVOA, Antônio. Os professores e sua formação. Lisboa: Dom Quixote, 1992.

TARDIF, Maurice. Saberes docentes e formação profissional. 3. ed. Petrópolis, RJ: Vozes, 2002. 